\title{
Health Literacy Improves the Lifestyle of Undergraduate in Education Students
}

\author{
Lisiane Goetz ${ }^{1} \&$ Renato C. Teixeira ${ }^{1}$ \\ ${ }^{1}$ Postgraduate Program in Health Education in the Amazon, University of State of Pará, Belém, Brazil \\ Correspondence: Lisiane Goetz, Postgraduate Program in Health Education in the Amazon, University of State \\ of Pará, Belém, Brazil. Tel: 55-919-9241-6431.
}

Received: August 11, 2020

Accepted: September 10, 2020

Online Published: September 22, 2020

doi:10.20849/jed.v4i3.787

URL: https://doi.org/10.20849/jed.v4i3.787

\begin{abstract}
The choices related to lifestyle habits, during the period of graduation at the university are decisive for the development of a healthy lifestyle and for combating the risk behaviors that lead to Chronic Non-communicable Diseases. This study aims to examine the relationship between a discipline focused on health literacy and the development of attitudinal components aimed at the competence of self-care and responsibility of pedagogy students, in relation to the choices that constitute their lifestyle. The investigation of this research indicates that the literacy and health promotion program developed during the Principles of Healthy Living for education students had a positive effect on the development of competence and responsibility for self-care in their lifestyle. Quantitative data were obtained using the socio-demographic questionnaire and validated scale of the Fantastic Lifestyle and the Global Physical Activity Questionnaire, at the beginning and end of the course. The results point to an improvement in lifestyle with an increase in the practice of recreational physical activity of vigorous intensity $(\mathrm{p}=0.0339)$ and in its frequency $(\mathrm{p}=0.0130)$. Still, there was a significant reduction in the level of physical inactivity ( $\mathrm{p}=0.0451)$, in addition to the evident improvement in lifestyle $(\mathrm{p}=0.0196)$, with all participants grouped in the categories "Good", "Very Good" and "Excellent" referring to lifestyle. This study showed that an approach to health education for university students is a positive initiative for teaching important skills to consolidate a healthy lifestyle.
\end{abstract}

Keywords: health education, university, lifestyle, self-care, competence

\section{Introduction}

Research claims that entering higher education provides a challenging period for maturation, in which the student needs to manage autonomy, independence and responsibility to make choices and balance academic, social and professional obligations (Bistricky, Harper, Roberts \& Cook, 2017; Gaviria, Blandón, Durango, \& Yepes, 2017), within a context favorable to abuse in the consumption of alcohol, coffee, drugs and tobacco and concomitant carelessness with food, physical activity, time for rest.

In studies on the life habits of university students, it is observed that the choices related to physical activity, food, sleep, drug and alcohol use, relationships, work and studies are determinant for the formation of the individual's lifestyle (Soares, Pereira \& Carnavarro, 2014; American College Health Association (ACHA), (2016); Barsell, Everhart, Miadich \& Trujillo, 2018; Guthold, Steven, Riley \& Bull, 2018 ). Despite the scientific evidence on the benefits of having a healthy lifestyle, the manifestation of risk behaviors in the university population is real, making this group vulnerable to developing Chronic Non-communicable Diseases (CNCD), (Caballero, Lopes, \& Delgado, 2018). The young university student also needs to deal with financial issues, relationships and diverse experiences that cause stress. These factors usually occur in an associated way, acting as a trigger for metabolic changes, which increase the risk of developing CNCD (Pôrto, Kümpel, Castro, Oliveira, \& Alfiere, 2015; Sarcona, Kovacs, Wright, \& Willians, 2017; Caballero et al., 2018; Calamidas \& Crowell, 2018). The World Health Organization reported that "chronic diseases are the leading cause of adult illness and death" in the world (World Health Organization [WHO], 2005), which are closely related to lifestyle, defined throughout life through individual options (Tassini, Val, Candido \& Bachur, 2017). If risky behaviors and chronic stress are maintained throughout adulthood, the individual may be more vulnerable to acquiring new diseases and worsening existing ones (Bistricky et al., 2017). 
In this context, health literacy, understood as a strategy through which it is possible to work on the human being's ability to learn, organize, reflect and understand information on health-related issues, to make choices (Valente et. al., 2019). This is because the young-adult phase is conducive to developing autonomy and responsibility, attitudes necessary for better management of healthy living habits. (Sarcona et al., 2017; Barsell et al., 2018). When the health literacy level is higher, Barsell et al., (2018) states that there is a reduction in habits and behaviors that are harmful to health, as education and promotion in this area provide the development of skills and attitudes corresponding to a style healthy lifestyle. Studies on health profiles in the university community in general, indicate the need to establish health literacy in higher education curricula, in addition to directing the approach of teaching themes and practices from the perspective of student interest and understanding (Fane \& Schulz, 2017; Calamidas \& Crowell, 2018). The information and educational experiences about health, received in the university environment, can influence students to change their lifestyle habits and, when they incorporate a healthy lifestyle, they become influencers of other people, potentiating the impact on society (Oliveira, 2017).

In this process of teaching learning about healthy behaviors, the teacher acts as a mediator between the student and the knowledge, guiding each one to self-assess and make balanced choices based on critical reflection on knowledge focused on life habits and their impact throughout of life (Calamidas \& Crowell, 2018). Still, it is recommended that the university provides a type of contextualized educational experience to establish a connection between theoretical knowledge and the students' life reality (Fane \& Schulz, 2017).

The literature review presents limited health education study, focused on training trained teachers and to apply specific health programs for primary school students (Pickett, Shepherd, Roderick \& Grace, 2017; Vamos, Xie \& Yeung, 2020). A targeted search revealed the lack of studies focused on the health education of the education student during his undergraduation, with the intention of promoting a personal experience that encourages him to establish a healthy lifestyle. However, there is agreement that there is a need for university health literacy programs for future teachers (Vamos et al., 2020), since the undergraduate stage comprises a propitious stage to expand knowledge and experience transformative experiences, which will increase their training (Sarcona et al., 2017).

This study intends to address this gap in the research literature, examining the impact of a discipline focused on health education, whose primary purpose is to promote and motivate the education graduate to acquire a healthy lifestyle. A Thus, this investigation focuses on examining the effectiveness of the Principles of Healthy Living, present in the mandatory curriculum matrix of the undergraduate education at Adventist College of the Amazon, identifying the lifestyle habits of these pedagogy students before and after the completion of this discipline.

The hypothesis of this study is that education students, when they become aware of what constitutes a healthy lifestyle, through the actions carried out during the health promotion discipline, will change their lifestyle habits.

The question that guides the research is: The presence of the discipline Principles of Healthy Living in the curriculum of undergraduate education at the Adventist College of the Amazon contemplates the purpose of developing self-care and responsibility in the group of students, to obtain or maintain a style of healthy life, since the objective of the discipline is the development of the attitudinal component?

This study contributes to the expansion of knowledge about health promotion and literacy of university students, respecting, as recommended by Piaget, the individuality of the student and his ability to assimilate, accommodate and balance new information (Piaget, 1973; Piaget, 1987), together with the valorization of social relations defended by Vygotsky (Vygotsky, 2007; Vygotsky, 2015), with the construction of new knowledge anchored in previous knowledge as indicated by Ausubel (Ausubel, 2000) and with the premise that the individual only learns what is meaningful to him, in accordance with his worldview, as instructed by educator Paulo Freire (Freire, 2019).

\section{Method}

This is a quantitative, longitudinal study with an analytical descriptive design, developed in 2020 . The study was carried out with authorization from the Adventist College of the Amazon and approval by the Ethics and Research Committee of the University of State of Pará, second advice CAAE: 25974646.0000.5174.

\subsection{Participants}

This study was carried out in the education graduation of the Adventist College of the Amazon, established in the state of Pará, northern region of Brazil. The sample of this study was for convenience, composed of students in the area of education, regardless of gender and included 26 participants, 24 of whom were female and 2 were male, enrolled in the Principles of Healthy Living. The participants voluntarily accepted to answer the questionnaires proposed in this research. 


\subsection{Procedures}

The application of the questionnaires, in digital format, was carried out at the beginning and end of the discipline Principles of Healthy Living, being applied respectively in the months of February and June 2020. The discipline classes took place once a week, for 60 minutes, for a period of five months, following the themes related to health literacy proposed by the Adventist College of the Amazon: (1) Principles of healthy living and their biblical health implications; (2) Physical health; (3) Mental health; (4) Spiritual health; (5) Family life; (6) Drug problems; (7) Adventist health philosophy. The classes were taught by a professor defined by the institution, without any interference from the researchers as to the methodology and strategies adopted.

\subsection{Instruments}

\subsubsection{Socio-Demographic Questionnaire}

Participants were asked about demographic information, such as age, sex, etc.

\subsubsection{Global Physical Activity Questionnaire (GPAQ)}

This instrument was created and validated by the World Health Organization (WHO, 2003), has an approach directed to the surveillance of risk factors for $\mathrm{CNCD}$, describing sedentary behaviors, physical activities in the daily routine, commuting and leisure activities through 16 questions. (Martins, 2017). GPAQ has three domains: (1) Activities at work; (2) Moving from one place to another; (3) Recreational activities; At the time of analysis, these domains are subdivided into sub-domains: (1a) Vigorous work; (1b) Moderate work; (2) Displacements; (3a) Vigorous recreation; (3b) Moderate recreation; (3c) Sitting, as defined in Global Physical Activity Analysis Guide (WHO, 2003). To analyze the results, the Metabolic Equivalent (MET) is used as a parameter to classify the intensity of physical activities.

\subsubsection{Fantastic Lifestyle Questionnaire}

This questionnaire was developed in 1984 by the Department of Medicine at McMaster University (Wilson, Nielsen \& Ciliska, 1984) and validated in Brazil (Rodriguez, Reis \& Pretroski, 2008). The purpose of this questionnaire is to examine the main determinants of an adequate lifestyle (Tassini et al., 2017). It consists of an instrument with twenty-five indicators distributed in nine categories, which form the acronym "FANTASTIC": F-family and friends; A- physical activity; N- nutrition; T- use of tobacco and drugs; A- alcohol use; S- sleep / seat belt / sex / stress; T- work / types of behavior; I- introspection; C- Health and sexual behaviors (Tassini et al., 2017). The questions are arranged according to the Likert scale, with 23 indicators having five alternatives and two having only two. The distribution of points gives: 0 for the first column, 1 for the second, 2 for the third, 3 for the fourth and 4 for the fifth column. For questions with two alternatives, 0 is considered for the first column and 4 points for the last column. The sum of the scores produces a total score of five categories, which classifies the participant from 0 to 100 points, being: Excellent ( 85 to 100 points), Very good (70 to 84 points), Good (55 to 69 points), Fair (35 to 54 points) and Needs improvement (0 to 34 points), (Rodriguez et al., 2008).

\subsection{Date Analysis}

The study design evaluated the data obtained in the questionnaires applied before and after the implementation of the discipline Principles of Healthy Living. Descriptive statistics captured positive characteristics of the participants, based on the calculation of position measures such as arithmetic mean and standard deviation. Analytical statistics was used to evaluate the results obtained between the groups. For the categorical variables of the sample profile, the G Adherence Test was used and in the comparison between groups the G Independence Test. In the evaluation between the means of the numerical variables, the related independent t-Student test was calculated for the pre and post discipline periods. Descriptive and analytical statistics were performed using the BioEstat ${ }^{\circledR} 5.4$ software. Significance level $\alpha=0.05$ or $5 \%$ was adopted, indicating the significant values with an asterisk $(*)$.

\section{Results}

The study sample consisted of 26 students, aged between 19 and 46 years old and the average age of 28 years old. The age group between 20 and 29 years old, presented a higher proportion (61.5\%), being statistically significant in relation to the others $(* \mathrm{p}<0.0001)$. There was a relevant proportion $(* \mathrm{p}=0.0224)$ of female participants $(92.3 \%)$, compared to male $(7.7 \%)$. Table 1 shows the descriptive data for the study participants. 
Table 1. Socio-demographic profile of education students

\begin{tabular}{lll}
\hline Socio-demographic profile & Frequency & (N = 26) \\
\hline Sex & & \\
\hline Female* & 24 & $92.3 \%$ \\
\hline Male & 2 & $7.7 \%$ \\
\hline Age & & \\
\hline$<20$ & 1 & $3.9 \%$ \\
\hline 20 a $29^{*}$ & 16 & $61.5 \%$ \\
\hline 30 a 39 & 5 & $19.2 \%$ \\
\hline$>=40$ & 4 & $15.4 \%$ \\
\hline Min / Median \pm SD / Max & $\mathbf{1 9} / \mathbf{2 8 . 0} \pm \mathbf{8 . 2} / \mathbf{4 6}$ & \\
\hline
\end{tabular}

Source: Questionnaire applied

Note 1. G Adherence Test

\subsection{Global Physical Activity Questionnaire (GPAQ)}

The questionnaire GPAQ was analyzed in its different domains and the results, compared at the beginning and after the conclusion of the discipline. In the first domain, which evaluates Activities at Work, no statistically significant difference was found ( $p>0.05$ ) in any of the questions, answered by the students. The same proportions were found, between the pre and post discipline responses, of students who develop work activities that require moderate efforts that lead to small increases in breathing or heartbeat (53.8\%). The number of days with activities of vigorous intensity decreased ( 6.0 to 4.5 days) and increased in relation to those of moderate intensity (3.8 to 4.4 days). As a result of this drop, the time spent on activity with vigorous intensity also decreased (4.8 to 3.3 hours), as shown in Table 2.

Table 2. Questionnaire GPAQ - Domain 1

\begin{tabular}{|c|c|c|c|}
\hline \multirow{2}{*}{ Domain 1: Activities at work } & \multicolumn{2}{|c|}{ Study group $(\mathrm{N}=\mathbf{2 6})$} & \multirow{2}{*}{ p-value } \\
\hline & $\begin{array}{l}\text { Pré } \\
\text { Intervention }\end{array}$ & $\begin{array}{l}\text { Pós } \\
\text { Intervention }\end{array}$ & \\
\hline $\begin{array}{l}\text { Does your work involve vigorous-intensity activity that } \\
\text { causes large increases in breathing or heart rate like for at } \\
\text { least } 10 \text { minutes continuously? }\end{array}$ & $(3.8 \%)$ & $2 \quad(7.7 \%)$ & 0.3693 \\
\hline $\begin{array}{l}\text { In a typical week, how many days do you do } \\
\text { vigorous-intensity activities as part of your work? }\end{array}$ & $6.0 \pm 0.0$ & $4.5 \pm 2.1$ & 0.2500 \\
\hline $\begin{array}{l}\text { How much time do you spend doing vigorous-intensity at } \\
\text { work on a typical day? }\end{array}$ & $4.8 \pm 0.0$ & $3.3 \pm 3.2$ & 0.3080 \\
\hline $\begin{array}{l}\text { Does your work involve moderate-intensity activity that } \\
\text { causes small increases in breathing or heart rate such as } \\
\text { brisk walking for at least } 10 \text { minutes continuously? }\end{array}$ & $14 \quad(53.8 \%)$ & $14 \quad(53.8 \%)$ & NSA \\
\hline $\begin{array}{l}\text { In a typical week, how many days do you do } \\
\text { moderate-intensity activities as part of your work? }\end{array}$ & $3.8 \pm 1.5$ & $4.4 \pm 1.0$ & 0.1529 \\
\hline $\begin{array}{l}\text { How much time do you spend doing moderate-intensity } \\
\text { activities at work on a typical day? }\end{array}$ & $1.7 \pm 1.3$ & $1.8 \pm 2.1$ & 0.4247 \\
\hline
\end{tabular}

Source: Questionnaire applied 
In domain 2, the questionnaire evaluates the time spent, on typical days, walking or using a bicycle to move between places, a statistically significant difference $\left({ }^{*} \mathrm{p}=0.0320\right)$ was identified between the pre and post discipline moments, in the evaluation of the time spent walking or cycling to travel on a typical day. In this question, the post-discipline result averaged above the pre-discipline result (48.2 and 34.2 minutes respectively), as shown in Table 3.

Table 3. Questionnaire GPAQ - Domain 2

\begin{tabular}{|c|c|c|c|}
\hline \multirow{3}{*}{ Domain 2: Travel to and from places } & \multicolumn{2}{|c|}{ Study group $(\mathrm{N}=\mathbf{2 6})$} & \multirow{3}{*}{ p-value } \\
\hline & Pré & Pós & \\
\hline & Intervention & Intervention & \\
\hline $\begin{array}{l}\text { Do you walk or use a bicycle (pedal cycle) for at least } \\
10 \text { minutes continously to get to and from places? }\end{array}$ & $13 \quad(50.0 \%)$ & $13 \quad(50.0 \%)$ & NSA \\
\hline $\begin{array}{l}\text { In a typical week, on how many days do you walk or } \\
\text { bicycle for at least } 10 \text { minutes continuously to get to } \\
\text { and from places? }\end{array}$ & $3.8 \pm 1.5$ & $3.8 \pm 1.3$ & NSA \\
\hline $\begin{array}{l}\text { How much time do you spend walking or bicycling for } \\
\text { travel on a typical day? }\end{array}$ & $34.2 \pm 30.5$ & $48.2 \pm 49.2$ & $0.0320 *$ \\
\hline
\end{tabular}

Source: Questionnaire applied

Note1. Independent t-Student test

In domain 3, in which the questionnaire evaluated physical and / or recreational activities, on typical days, a statistically significant difference $(* p=0.0339)$ was observed in the proportion of students who practice sports, exercises or recreational activities of vigorous exercises, with an increase in the post-intervention assessment $(42.3 \%$ to $57.7 \%)$. There was also an increase in the proportion of students practicing sports, exercises or recreational activities of moderate intensity, in the post-discipline evaluation (50.0\% to $57.7 \%)$, this increase being not statistically significant $(\mathrm{p}=0.3204)$.

The number of days of practicing sports, exercises or recreational activities of vigorous intensity, after performing the discipline, showed a statistically significant increase $(* p=0.0130)$ in relation to the initial period $(1.8$ to 2.9 days). The practice of moderate intensity in the post-intervention assessment was close to the initial assessment (2.9 and 3.0 respectively), with no statistically significant difference between them $(p=0.3051)$.

The duration of these activities, both in vigorous and moderate intensity, did not show a statistically significant difference $(\mathrm{p}>0.05)$ in the comparison between the evaluation periods, as shown in Table 4.

Table 4. Questionnaire GPAQ - Domain 3

\begin{tabular}{|c|c|c|c|}
\hline \multirow[b]{2}{*}{ Domain 3: Physical and recreational activity } & \multicolumn{2}{|c|}{ Study group $(\mathrm{N}=26)$} & \multirow[b]{2}{*}{ p-value } \\
\hline & $\begin{array}{l}\text { Pré } \\
\text { Intervention }\end{array}$ & $\begin{array}{l}\text { Pós } \\
\text { Intervention }\end{array}$ & \\
\hline $\begin{array}{l}\text { Do you do any vigorous-intensity sports, fitness or recreational } \\
\text { (leisure) activities that cause large increases in breathing or heart } \\
\text { rate like for at least } 10 \text { minutes continuously? }\end{array}$ & $(42.3 \%)$ & $(57.7 \%)$ & $0.0339 \%$ \\
\hline $\begin{array}{l}\text { In a typical week, on how many days do you do vigorous-intensity } \\
\text { sports, fitness or recreational (leisure) activities? }\end{array}$ & $1.8 \pm 1.5$ & $2.9 \pm 1.9$ & $0.0130 * *$ \\
\hline $\begin{array}{l}\text { How much time do you spend doing vigorous-intensity sports, } \\
\text { fitness or recreational activities on a typical day? }\end{array}$ & $1.1 \pm 1.0$ & $1.0 \pm 1.1$ & NSA \\
\hline $\begin{array}{l}\text { Do you do any moderate-intensity sports, fitness or recreational } \\
\text { (leisure) activities that cause large increases in breathing or heart } \\
\text { rate like for at least } 10 \text { minutes continuously? }\end{array}$ & $(50.0 \%)$ & $(57.7 \%)$ & 0.3204 \\
\hline
\end{tabular}




\begin{tabular}{|c|c|c|c|}
\hline $\begin{array}{l}\text { In a typical week, on how many days do you do moderate-intensity } \\
\text { sports, fitness or recreational (leisure) activities? }\end{array}$ & $3.0 \pm 1.1$ & $2.9 \pm 1.4$ & 0.3051 \\
\hline $\begin{array}{l}\text { How much time do you spend doing moderate-intensity sports, } \\
\text { fitness or recreational activities on a typical day? }\end{array}$ & $1.5 \pm 0.6$ & $1.0 \pm 0.5$ & 0.0719 \\
\hline
\end{tabular}

Source: Questionnaire apllied

Note 1. Chi-Square Independence Test

Note 2. Independent t-Student test

In relation to sedentary behavior, assessed in domain 4 of the questionnaire, a statistically significant difference ${ }^{*}$ $\mathrm{p}=0.0451$ ) was found in the time spent sitting or lying down by students between the period before and after the discipline classes (5.1 to 3.9 hours), as table 5 .

Table 5. Questionnaire GPAQ - Domain 4

\begin{tabular}{lllll}
\hline \multirow{2}{*}{ Domain 4: Sedentary behaviour } & \multicolumn{2}{l}{ Study group (N=26) } & \multicolumn{2}{c}{ p-value } \\
\cline { 2 - 3 } & Pré Intervention & Pós Intervention & \\
\hline $\begin{array}{l}\text { How much time do you usually spend sitting or } \\
\text { reclining on a typical day? }\end{array}$ & 5.1 & 3.9 & $\mathbf{0 . 0 4 5 1 *}$ \\
\hline
\end{tabular}

Source: Questionnaire applied

Note1. Independent t-Student test

\subsection{Questionário Estilo de Vida Fantástico}

In relation to Lifestyle, the final classification, through the consolidated score of the applied questionnaire, showed a statistically significant improvement $(* p=0.0196)$ in the evaluation after the discipline. It is evident in the initial assessment that $19.2 \%$ of the students had a regular lifestyle, whereas in the final assessment, none of them presented this classification. The Very Good and Excellent classifications also showed an increase in the proportion of students, as shown in Table 6.

Table 6. Lifestyle classification

\begin{tabular}{lllll}
\hline \multirow{2}{*}{ Lifestyle Assessment } & \multicolumn{3}{l}{ Study group (N=26) } \\
\cline { 2 - 6 } & Pré Intervention & \multicolumn{2}{l}{ Pós Intervention } \\
\hline Fair: Provides some health benefit, but it also presents risks. & 5 & $19.2 \%$ & 0 & $0.0 \%$ \\
\hline Good: Provides many health benefits. & 6 & $23.1 \%$ & 3 & $11.5 \%$ \\
\hline Very good: Provides adequate influence for health. & 10 & $38.5 \%$ & 17 & $65.4 \%$ \\
\hline Excellent: Provides excellent health influence. & 5 & $19.2 \%$ & 6 & $23.1 \%$ \\
\hline
\end{tabular}

Source: Questionnaire applied

Note $1 .{ }^{*} \mathrm{p}=0.0196$

Note 2. G Independence Test

\section{Discussion}

The aim of this study was to examine the relationship between a discipline aimed at health literacy and the development of attitudinal components aimed at the competence of self-care and responsibility of students, in relation to the choices that constitute the lifestyle. As far as it was possible to investigate, we do not know of a previous study that worked on health education in the mandatory curriculum matrix of the undergraduate in education with the primary intention of promoting a personal experience that encourages the pedagogy student to establish a healthy lifestyle. This research supports a previous study that highlights the need to implement efficient 
mechanisms in education and health promotion with individuals, motivating them to make changes and consolidate a healthy lifestyle, as highlighted (Caballero, et al., 2018). Since these students, upon graduating from university, will have the responsibility to develop health literacy programs for primary school children, we assume that experimenting with a healthy lifestyle will shape their beliefs, skills and teaching intent, as highlights (Vamos et al., 2019). The results from the GPAQ show that the students' attitudes are related to their autonomy to make choices. In Table 2, it is observed that the activities during work did not change, which can be understood as an inherent characteristic of the work context and peculiarities of the function performed, over which there is little autonomy, preventing significant change. In Table 3 , in contrast, there was a considerable increase $(p=0.0320)$ in the travel time between places on typical days, which points to the student's intention to move through more active means. Regarding the domain that evaluated physical and recreational activities, where the participant's autonomy is total, the result shown in Table 4 shows a significant increase $(p=0.0339)$ in individuals who chose to practice activities with vigorous intensity, as well as an increase in number of days of practice $(p=0.0130)$. Regarding recreational physical activities of moderate intensity, there was no significant difference after the end of the discipline's classes, which may indicate a group of students who are satisfied or accommodated with the level of effort made, having not been influenced to intensify physical exercises and recreational activities. The findings of the last domain of the GPAQ showed a significant reduction in sedentary behavior $(p=0.0451)$, as detailed in Table 5. The lower levels of sedentary lifestyle revealed in the survey indicate an effective gain for students' health, since every effort applied in reducing sedentary lifestyle is fundamental to fight CNDC (Caballero et al., 2018). This research also used the Fantastic Lifestyle questionnaire to examine the students' attitudinal component in relation to other variables that make up a person's lifestyle. Table 6 presents statistically significant data $(\mathrm{p}=$ 0.0196), indicating a considerable improvement in the lifestyle of students in the pedagogy course. The classification "Good" is the desirable reference, according to (Rodriguez, 2008), because from this categorization, the need to change life habits is less. The result presented in Graph 01, highlights the migration of individuals from the "Fair" category to the others, which shows an improvement in the lifestyle of $19,2 \%$ of the students. It is possible to notice an exponential growth of $69.9 \%$ in the "Very Good" category, indicating, according to Table 6 , that $38.5 \%$ of the students presented attitudes that establish an adequate influence for health. There was also a growth of $20.31 \%$ in the classification "Excellent", which (Rodriguez, 2008) describes as a lifestyle that provides great influence on health.

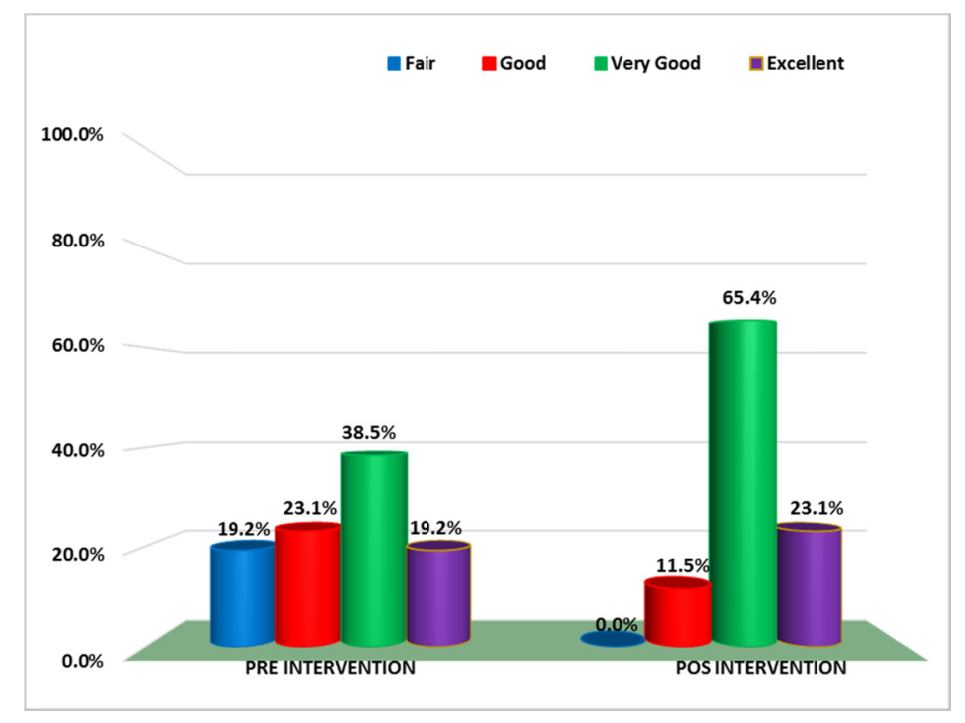

Figure 1. Lifestyle classification

Source: Questionnaire applied

Nota 1. *p $=0.0196$ Teste G Independência

This study showed that the health literacy program developed during the discipline Principles of Healthy Living had a positive and relevant effect on the development of self-care competence and responsibility for their life habits. Thus, this research confirmed the hypothesis that pedagogy students, when they became aware of what constitutes a healthy lifestyle, decided to make choices in search of a healthier lifestyle. 


\subsection{Limitations}

A limitation is the use of a convenience sample, which restricts the number of participants, which can be considered as under-representation or over-representation of a specific group. Another limitation is the duration of the Principles of Healthy Living, limited to one semester for completion, which restricts the analysis of the influence on students in relation to the complete period of graduation. Understanding the development of an attitudinal component related to the formation and / or consolidation of a healthy lifestyle would be more striking when evaluating the transformation made in the graduate.

\subsection{Future Research}

Future investigations need to evaluate the content of the teaching program related to the most appropriate approach according to the perception of the group of students and their needs. This stage in the life of the university student is an opportunity to be explored by universities, so that the influence received during graduation goes beyond the perimeter of the university campus and powerfully influences society.

\section{Conclusion}

This study demonstrated that the presence of a discipline focused on health literacy can trigger improvements in the development of a healthy lifestyle in a population recognized as vulnerable to the development of Chronic Noncommunicable Diseases, but also as a population susceptible to influence and prone to changes. Among the data collected in this study, the lifestyle classification, using the Fantastic Lifestyle Questionnaire, stood out exponentially, revealing that in the short period of five months, the discipline Principles of Healthy Living had a positive impact on changing habits of life of the participants. An analysis of the pre and post intervention results, pointed to the migration of all students incorporated as "Regular" to a category of better qualification, as well as indicated a reduction of necessary in the category "Good", revealing the rupture with harmful practices to health in favor of a healthy life, for a significant part of the sample. In relation to the "Very Good" and "Excellent" categories, as they point out as practicing good life habits, there was also growth, which demonstrates the importance of permanent teaching and encouraging the consolidation of good habits. However, the study did not attempt to question the themes chosen for this discipline, nor the way they were raised, in order to verify the admissibility of improvements, from the students' perspective. Thus, the value of this research is in confirming that a transversal discipline with a proposal for health literacy needs to be offered, compulsorily, throughout the trajectory of higher education, as the positive impact is real and its influence may exceed the campus boundaries. It is worth stressing that a teacher of basic education, with this training, is better able to use health habits for the new generations, being an agent that disseminates the culture of health and the prevention of Chronic Non-Communicable Diseases. In addition, this investigation opens up new possibilities for observation and examination of transversal disciplines aimed at health literacy, in the search for clarification on the selection of content and work methodologies for the development of the attitudinal component of education students. This is because the evidence collected in this study confirms that health literacy results in modeling the student's lifestyle, with possibilities for a more complete education. Finally, it is evident that the university is a favorable space to promote the healthy development of the student, stimulating understanding and commitment to personal health (Sarmiento, 2017). Thus, we consider it necessary that the education student's education promotes integral education, in view of the gains in the personal life of the student and their preparation for future performance in basic education.

\section{References}

American College Health Association. (2016). American College Health Association-National College Health Assessment II: Fall 2016 Reference Group Executive Summary. Hanover, MD: American College Health Association.

Ausubel, D. P. (2000). The acquisition and retention of knowledge: a cognitive view. Dordrecht: Kluwer Academic Publishers.

Barsell, J., Everhart, R. S., Miadich, S. A., \& Trujillo, M. A. (2018). Examining Health Behaviors, Health Literacy, and Self-efficacy in College Students with Chronic Conditions. American Journal of Health Education, 49(5), 305-311. https://doi.org/10.1080/19325037.2018.14867

Bistricky, S. L., Harper, K. L., Roberts, C. M., \& Cook, D. M. (2017). Understanding and Promoting Stress Management Pratices Among College Students Through an Integrates Health Behavior Model. American Journal of Health Education, 49(1), 12-27. https://doi.org/10.1080/19325037.2017.1377651 
Caballero, L. G. R., Lopes, A. L. M., \& Delgado, E. M. G. (2018). Actividad física em el Tiempo libre y consumo de frutas y verduras em estudiantes universitários. Hacia Promoc Salud, 23(2), 90-103. https://doi.org/10.17151/hpsal.2018.23.2.7

Calamidas, E. G., \& Crowell, T. L. (2018). A Content Analysis of College Students' Health Behaviors. American Journal of Health Education, 49(3), 133-146. https://doi.org/10.1080/19325037.2018.1428699

Fane, J., \& Schulz, S. (2017). Working against "pedagogic work": Challenges to engaging pre-service tezchers in critical health education. Health Education, 117, 511-528. http://doi.org/10.1108/HE-10-2016-0042

Gaviria, H. A. M., Blandón, D. A. S., Durango, M. P. P., \& Yepes, T. A. (2017). Overweight and Obesity Conditions: Prevalence and Associated Risk Factors in Nursing Students in a Public University in Medellín. Colombia Invest Educ Enferm, 35(2), 191-196. https://doi.org/10.17533/udea.iee.v35n2a08

Guthold, R., Stev, A., Riley, L. M., \& Bull, F. C. (2018). Worldwide trends in insufficient physical activity from 2001 to 2016: a pooled analysis of 358 population-based surveys with 1.9 million participants. The Lancet Global Health, 6, 1077-1086. https://doi.org/10.1016/S2214-109X(18)30357-7

Oliveira, C. S. (n.d.). Health promotiong university: a literature review. Unpublished Master's Thesis. Federal Universitity of Bahia, Salvador, Brazil.

Paulo, F. (2019). Pedagogia da autonomia: saberes necessários à prática educativa. $60^{a}$ Edição. São Paulo: Paz e Terra.

Piaget, J. (1973). Biologia e conhecimento (Guimarães, F.M., Trans.). São Paulo: Vozes.

Piaget, J. (1987). O nascimneto e a inteligência na criança (Cabral, A., Trans.). Rio de Janeiro: LTC.

Pickett, K., Rietdijk, W., Byrne, J., Sheperd, J., Roderick, P., \& Grace, M. (2017). Teaching health education: A thematic analysis of early career teachers' experiences following pre-service health training. Health Education, 117(3), 323-340. https://doi.org/10.1108/HE-10-2016-0051

Pôrto, E. F., Kümpel, C., Castro, A. A. M., Oliveira, I. M., \& Alfiere, F. M. (2015). How life-style has been evaluated: a systematic review. Acta Fisiátr, 22(4), 199-205. https://doi.org/10.5935/0104-7795.20150038

Rodriguez, A. C. R., Reis, R. S., \& Pretroski, E. L. (2008). Brazilian Version os a Lifestyle Questionnaire: Translation and Validation for Young Adults. Arq Bras Cardiol, 91(2), 92-98. https://doi.org/10.1590/s0066-782x2008001400006

Sarcona, A., Kovacs, L., Wrigth, J., \& Williams, C. (2017). Differences in Eating behavior, Physical Activity and Health-related Lifestyle Choices between Users and Nonusers of Mobile health Apps. American Journal of Health Education, 48(5), 298-305. https://doi.org/10.1080/19325037.2017.1335630

Sarmiento, J. P. (2017). Healthy universities: mapping health-promotion interventions. Health Education, 117 , 162-175. http://doi.org/10.1108/HE-07-2016-0028

Soares, A. M., Pereira, M., \& Canavarro, J. P. (2014). Health and Quality of Life in the Transition to Higher Education. Psicologia, Saúde \& Doenças, 15(2), 356-379.

Tassini, C. C., Val, G. R., Candido, S. S., \& Bachur, C. K. (2017). Assessment of the Lifestyle of University Students in the Healthcare Area Using the Fantastic Questionnaire. International Journal of Cardiovascular Sciences, 30(2), 117-122.

Valente, A. L., Alves, B. C., Queiroz, E., Gonçalves, I. A., Magalhães, L. A., Avelar, M. T., ... Silva, S. E. O. (2019). Health literacy: Review of a language to be constructed - Observational study. Paper presented at the 17th Scientific Journey of the University Hospital of Brasilia. Brasília, Distrito Federal, Brazil. Retrieved

from https//www.even3.com.br/anais/17jornadacientificadohub/141032-ALFABETIZACAO-EM-SAUDE--REV ISAO-SOBRE-UMA-LINGUAGEM-A-SER-CONSTRUIDA--ESTUDO-OBSERVACIONAL>

Vamos, S. D., Xie, E. X., \& Yeung, P. (2020). Effects of a Health Education Course on Pre-Service Teachers' Perceived Knowledge, Skills, Preparedness, and Beliefs in Teaching Health Education. Journal of School Health, 90, 224-233. https://doi.org/10.1111/josh.12868

Vygotsky, L. S. (2007). A formação Social da mente. São Paulo, SP: Martins Fontes. $7^{\text {a }}$ Edição.

Vygotsky, L. S. (2015). Pensamento e Linguagem. São Paulo, SP: Martins Fontes. $4^{\mathrm{a}}$ Edição/2008 - $4^{\mathrm{a}}$ Reimpressão/2015. 
Wilson, D. M., Nielsen, E., \& Ciliska, D. (1974). Lifestyle assessment: testing fantastic instrument. Can Fam Physician, 30, 1863-1864. Retrieved from https://www.ncbi.nlm.nih.gov/pmc/articles/PMC2154238/

World Health Organization. (2003). Global Physical Activity Questionnaire -GPAQ. Analysis guide. Geneva, Switzerland: World Health Organization. Retrieved from https://www.who.int/ncds/surveillance/steps/STEPS_QbyQ_Guide.pdf

World Health Organization., \& Preventing Chronic Deseases a vital investment. (2005). Geneva, Switzerland: World Health Organization. Retrieved from

https;//www.who.int/chp/chronic_disease_report/contents/part1.pdf?ua=1

\section{Copyrights}

Copyright for this article is retained by the author(s), with first publication rights granted to the journal.

This is an open-access article distributed under the terms and conditions of the Creative Commons Attribution license (http://creativecommons.org/licenses/by/4.0/). 